\title{
Hydramethylnon potentiation in Solenopsis invicta by infection with the microsporidium Thelohania solenopsae
}

\author{
Steven M. Valles* and Roberto M. Pereira \\ USDA-ARS, Center For Medical, Agricultural and Veterinary Entomology, 1600 SW 23rd Drive, Gainesville, FL 32608, USA
}

Received 22 August 2002; accepted 12 November 2002

\begin{abstract}
Laboratory and field evaluations were conducted in which hydramethylnon treatments were made against Solenopsis invicta individuals and colonies that were either infected or uninfected with Thelohania solenopsae. In laboratory experiments, polygynous $T$. solenopsae-infected colonies of $S$. invicta exhibited significantly greater cumulative mortality than uninfected colonies when exposed to hydramethylnon, a respiratory-inhibiting insecticide. By day 21 , nearly $100 \%$ of the individuals in the $T$. solenopsaeinfected colonies were dead whereas only about $50 \%$ of the individuals in the uninfected colonies were dead. In addition to a higher cumulative mortality among $T$. solenopsae-infected workers, queens from infected colonies exhibited higher mortality than those from uninfected colonies. Similar results were observed in field studies in which fire ant-infested pasture was treated with hydramethylnon. The number of $T$. solenopsae-infected colonies decreased much faster relative to uninfected colonies in the same area. The initial rate of decline was 1.3 mounds/plot/day among $T$. solenopsae-infected colonies compared with a decrease of 0.4 mounds/ plot/day among uninfected colonies. Insecticide toxicity bioassay data supported our hypothesis that T. solenopsae infection can potentiate the toxicity of hydramethylnon. T. solenopsae-infected workers were 2.4-fold more susceptible to hydramethylnon than uninfected workers in toxicity bioassays.
\end{abstract}

(C) 2002 Elsevier Science (USA). All rights reserved.

Keywords: Microsporidium; Thelohania solenopsae; Insecticide potentiation; Solenopsis invicta; Hydramethylnon; IPM; Insecticide toxicity

\section{Introduction}

The red imported fire ant, Solenopsis invicta Buren, was introduced into the United States at Mobile, Alabama, in the early 1930s (Lofgren et al., 1975). It has since spread widely throughout the southeastern states and has been found recently in New Mexico, Arizona, and California (Williams et al., 2001). Despite the availability of several insecticides for use against fire ants, they provide only a temporary reduction in the level of infestation; population levels invariably rebound in the absence of insecticides. In areas where $S$. invicta is indigenous, the infestation rate is significantly lower compared with areas in which it has been introduced (e.g., the United States) (Porter et al., 1992). This disparity is common among introduced species because the

\footnotetext{
${ }^{*}$ Corresponding author. Fax: 1-352-374-5818.

E-mail address: svalles@gainesville.usda.ufl.edu (S.M. Valles).
}

area of introduction is typically devoid of natural enemies.

Realistically, any hope of achieving sustainable control of $S$. invicta populations across its range in the United States will depend on the use of biological control agents. Thelohania solenopsae Knell, Allen \& Hazard is a microsporidium that infects $S$. invicta and Solenopsis richteri Forel in indigenous areas (Briano et al., 1995). This entomopathogen has been found in the United States (Williams et al., 1998) and reported to produce a debilitating effect on fire ant colonies (Williams et al., 1999) often leading to colony elimination through attrition (Oi and Williams, 2002). T. solenopsae, like all microsporidia, apparently lacks mitochondria (Weidner, 1970) and, as a result, are thought to utilize host-derived ATP for much of their energy needs (Mathis, 2000; Weidner et al., 1999). Despite the absence of mitochondria, a number of genes for mitochondrial metabolic enzymes were found to be retained in the genome of Encephalitozoon cuniculi Levaditi, Nicolau \& 
Schoen (Katinka et al., 2001) and Trachipleistophora hominis Hollister et al. has been shown to possess tiny $(50 \times 90 \mathrm{~nm})$ organelles with double membranes (Williams et al., 2002). Although these recent data suggest that ancestors of microsporidia possessed mitochondria, the pathways for satisfying energy demands in these organisms are not currently understood.

Assuming that the host satisfies much of the energy needs of microsporidia, we hypothesized that a respiratory-inhibiting insecticide, like hydramethylnon (Hollingshaus, 1987), could be more efficacious against fire ant colonies infected with $T$. solenopsae than uninfected colonies. In an effort to test this hypothesis, we conducted laboratory and field evaluations in which hydramethylnon treatments were made against $S$. invicta individuals and colonies that were either infected with $T$. solenopsae or uninfected.

\section{Materials and methods}

\subsection{Laboratory insecticide bioassays}

Polygynous $S$. invicta colonies were excavated from areas in Gainesville, FL, and transferred to rearing trays using the floating technique described previously (Jouvenaz et al., 1977). Colonies were immediately assessed by phase-contrast microscopy to determine whether or not they were infected with $T$. solenopsae. Individual worker ants (20 large and 20 small) were homogenized in approximately $50 \mu \mathrm{l}$ of water and subsequently examined under a microscope at $400 \times$. Each ant was observed for 3-5 min. Infection rates were arbitrarily considered "high" if $>75 \%$ or "low" if $<50 \%$ of 40 individual workers were observed to possess $T$. solenopsae spores. No attempt was made to quantify the spore titer in individual ants. Colonies were labeled "uninfected" if no spores were observed in 40 insects.

Fragment colonies comprised of brood $(0.25 \mathrm{~g})$, workers $(0.5 \mathrm{~g})$ and queens ( 2 individuals) were prepared from field colonies exhibiting each level of $T$. solenopsae infection (i.e., high, low, and uninfected). These fragment colonies were placed into an artificial rearing cell composed of a Petri dish $(9 \mathrm{~cm}$ diameter $\times 1.5 \mathrm{~cm}$ height $)$ containing moistened (4 $\mathrm{ml}$ water) dental Castone (Dentistry International, St. Louis, MO; $0.5 \mathrm{~cm}$ depth). Each rearing cell was held in a plastic shoe box $(32 \times 19 \times 11.5 \mathrm{~cm})$, the inner sides of which were coated with Fluon (Asahi Glass Company, Bayonne, NJ) to prevent ant escape. The colonies were provided a test tube of water and allowed to acclimate for $48 \mathrm{~h}$. The experiment was repeated three different times $(7$ November 2001, 25 February 2002, and 8 March 2002). In each experiment, two fragment colonies were prepared from each of low infected $(n=3)$, high infected $(n=3)$, and uninfected $(n=2)$ field colonies. For each replicate, one fragment colony was provided $1 \mathrm{~g}$ of Siege-Pro (0.73\% hydramethylnon; BASF Corporation, Research Triangle Park, NC) and the other with the insecticidefree carrier consisting of defatted corngrit containing $30 \%$ soybean oil by weight as a control. Treatments were placed on a $16-\mathrm{cm}^{2}$ plastic weigh boat. Ants were allowed access to their respective treatment (Siege-Pro or control) for 4 days. After 4 days the treatments were removed and replaced with a solution of sucrose $(1 \%)$ in a cotton-stoppered test tube and crickets, ad libitum, for the duration of the study. Dead ants (workers and queens) were counted, recorded, and removed every $24 \mathrm{~h}$ from each colony. Mortality in the control fragment colony was subtracted from the mortality of each respective Siege-Pro-treated fragment colony to correct for natural mortality. Cumulative, corrected mortality for each colony was recorded (days 1-11,14-16, 18, and 21) and used to make comparisons among the different $T$. solenopsae-infection categories by analysis of variance (ANOVA) using day as a by-variable followed by Scheffe's multiple comparison procedure to separate the means (SAS Institute, 1988).

The toxicities of hydramethylnon and chlorpyrifos (ChemService, West Chester, PA) were assessed for $T$. solenopsae-infected and uninfected $S$. invicta workers. Worker ants were topically treated with an acetone solution of chlorpyrifos $(2,3,4,5,6 \mathrm{ng} / \mathrm{ant})$ in $0.5 \mu \mathrm{l}$ or were allowed to feed on a known concentration $(1,2,4$, $8,16 \mu \mathrm{g} / \mu \mathrm{l}$ ) of hydramethylnon (in soybean oil). Control ants were treated with acetone devoid of chlorpyrifos or soybean oil devoid of hydramethylnon. Groups of 10 medium sized workers $(1-1.5 \mathrm{mg})$ from each colony type (T. solenopsae-infected or uninfected) were placed into $50-\mathrm{ml}$ plastic souffle cups containing $10 \mathrm{ml}$ of cured Castone. A small hole (2.5-mm diameter) was cut into the bottom of the souffle cup to expose the Castone. The cup was placed directly onto a water-saturated sponge which kept the castone within the cups moist. At least five insecticide concentrations causing $>0 \%$ and $<100 \%$ mortality were chosen for each bioassay, and a minimum of three replications (in time) were conducted. Because chlorpyrifos is a fast-acting anticholinesterase and hydramethylnon is a slow-acting respiratory poison, ant mortality was assessed at $24 \mathrm{~h}$ for chlorpyrifos and $96 \mathrm{~h}$ for hydramethylnon. Ant mortality was corrected using Abbott's formula (Abbott, 1925) and the effective doses, concentrations, or times were estimated by probit analysis (Finney, 1971).

Mortality comparisons were also made between polygyne $T$. solenopsae-infected and uninfected worker ants in the absence of an introduced treatment. Worker ants were provided only a water source. Mortality for infected and uninfected workers was determined by counting the number of dead in each group daily. Lethal time determinations were estimated using probit analysis with time as the independent variable. The experi- 
ment was replicated three times (in time and space) with a sample size of 60 worker ants per replicate.

\subsection{Field evaluations}

The effect of hydramethylnon (Siege-Pro) treatment on the proportion of $T$. solenopsae-infected to uninfected $S$. invicta colonies was evaluated on pastureland in Gainesville, FL. Four randomly chosen $500 \mathrm{~m}^{2}$ subplots in an $18,000 \mathrm{~m}^{2}$ pasture were sampled for red imported fire ant mounds (mounds are obvious in active colonies). Each mound within the subplots was identified by flagging and a sample of ants (50-500) was taken from each. The samples were evaluated for the presence of $T$. solenopsae infection by detection of spores using phase-contrast microscopy. The entire $18,000 \mathrm{~m}^{2}$ area containing the 4 subplots was treated with Siege-Pro at a rate of $1.83 \mathrm{~kg} / \mathrm{ha}$ as described previously (Williams et al., 1983). The treated areas were surveyed for fire ant mounds and examined for $T$. solenopsae infection on days $0,14,21$, and 56 . The proportion of infected to uninfected mounds was compared at each sampling time by Student's $t$ test.

\section{Results and discussion}

In laboratory experiments, $T$. solenopsae-infected colonies of $S$. invicta exhibited significantly greater cumulative mortality than uninfected colonies when exposed to hydramethylnon (Fig. 1). No significant differences in cumulative mortality were observed between colonies with high and low infections of $T$. solenopsae. By day 21 , nearly $100 \%$ of the individuals in the T. solenopsae-infected colonies were dead while only about $50 \%$ of the individuals in the uninfected colonies were dead. The mortality rate was considerably higher among the $T$. solenopsae-infected colonies during the first 7-10 days compared with uninfected colonies. Conversely, during the last 10-13 days of the experiment, the mortality rates of the $T$. solenopsae-infected and uninfected colonies paralleled each other. The initial higher rate of mortality in the infected colonies is most likely the result of increased stress placed on the ant host by $T$. solenopsae infection. This effect would be especially evident if $T$. solenopsae was utilizing host-derived ATP. In such a situation, the ATP demand by $T$. solenopsae could enhance (potentiate) the toxic effects of hydramethylnon.

In addition to a higher cumulative mortality among T. solenopsae-infected workers, queens from infected colonies also exhibited higher mortality than those from uninfected colonies (Fig. 2). In fact, a dose relationship between the level of $T$. solenopsae infection and queen mortality was observed. Only $13 \%$ of queens from uninfected colonies $(n=8)$ were killed within 21 days,

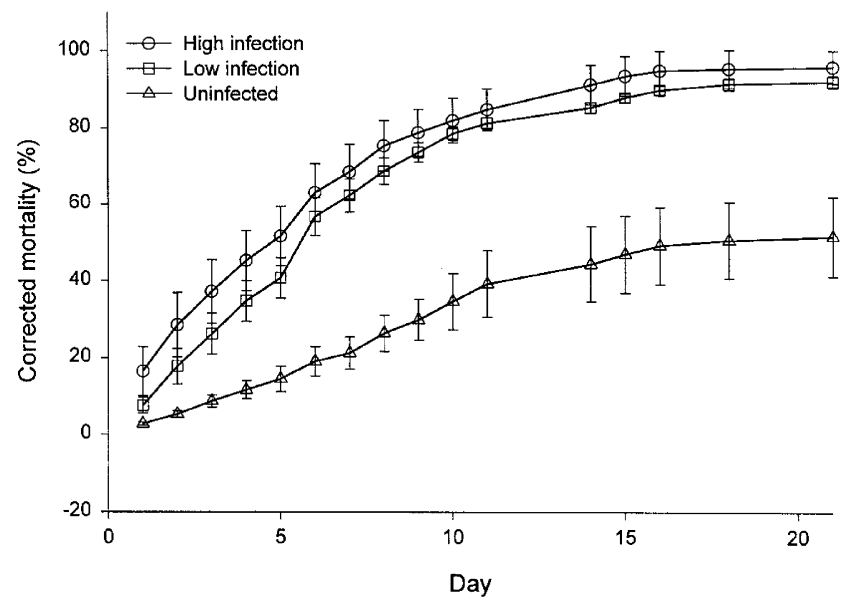

Fig. 1. Mean cumulative mortality from laboratory colonies of Solenopsis invicta exhibiting no detectable Thelohania solenopsae infection (uninfected), low infection $(<50 \%)$, or high infection $(>75 \%)$ after treatment with hydramethylnon (Siege-Pro). Data were corrected for control mortality (absence of insecticide treatment). No significant differences were observed between colonies with low and high infections of $T$. solenopsae. Significant differences were observed between infected (low and high) and uninfected colonies on days $4(F=4.5$; $P=0.025), 5(F=5.6 ; P=0.012), 6(F=8.9 ; P=0.002), 7(F=11.7$; $P=0.0005), 8(F=15.6 ; P<0.0001), 9(F=19.5 ; P<0.0001), 10$ $(F=19.6 ; \quad P<0.0001), \quad 11 \quad(F=18.5 ; \quad P<0.0001), 14 \quad(F=19.3$; $P<0.0001), 15(F=19.4 ; P<0.0001), 16(F=18.5 ; P<0.0001), 18$ $(F=18.8 ; P<0.0001)$, and $21(F=20.6 ; P<0.0001)$. In all cases $\mathrm{df}=2,19$.

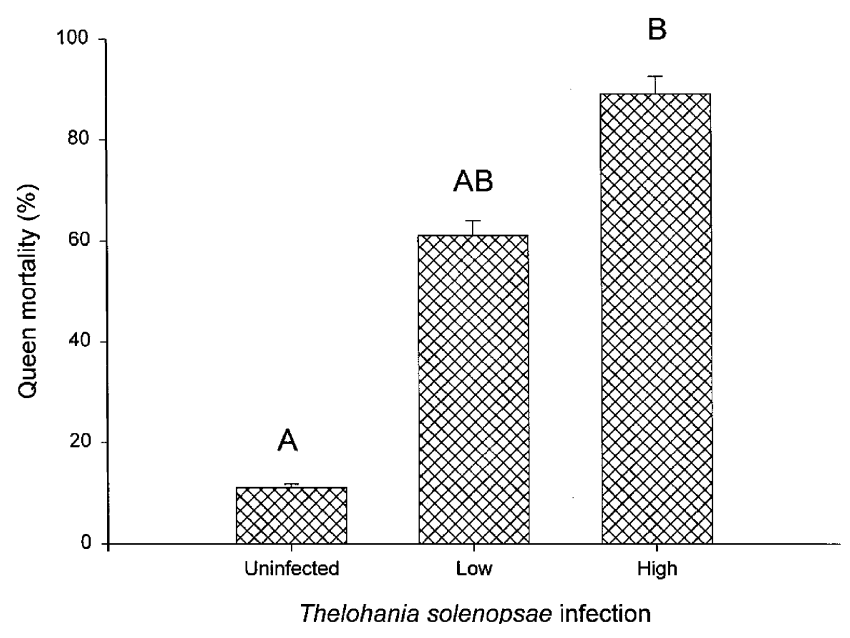

Fig. 2. Mean cumulative mortality of Solenopsis invicta queens from laboratory colonies exhibiting different levels of Thelohania solenopsae infection 21 days after treatment with hydramethylnon (Siege-Pro). Bars with different letters are significantly different by Scheffe's multiple comparison procedure $(n=8,18,18$ for uninfected, low and high infection, respectively).

while 61 and $89 \%$ mortality was observed among queens from colonies exhibiting low level $(n=18)$ and high level $(n=18) T$. solenopsae infections, respectively.

The insecticide toxicity bioassay data (Table 1) supported our hypothesis that $T$. solenopsae infection can 
Table 1

Lethal dose and time values for Thelohania solenopsae-infected and uninfected Solenopsis invicta colonies

\begin{tabular}{llllllc}
\hline$T$. solenopsae infection & Insecticide & $n$ & $\chi^{2}$ & df & Slope $\pm \mathrm{SE}$ & $\mathrm{EX}_{50}(95 \% \mathrm{CI})^{\mathrm{a}}$ \\
\hline Positive & Chlorpyrifos & 180 & 3.8 & 3 & $5.6 \pm 0.8$ & $2.47(2.19-2.71)$ \\
Negative & Chlorpyrifos & 230 & 3.4 & 3 & $8.4 \pm 0.9$ & $2.30(2.15-2.45)$ \\
Positive & Hydramethylnon & 250 & 0.5 & 3 & $1.2 \pm 0.2$ & $4.0(2.86-5.61)$ \\
Negative & Hydramethylnon & 250 & 2.5 & 3 & $1.1 \pm 0.2$ & $9.79(6.75-17.90)$ \\
Positive & None & 180 & 5.6 & 5 & $3.0 \pm 0.2$ & $7.70(7.24-8.26)$ \\
Negative & None & 180 & 4.3 & 5 & $1.5 \pm 0.3$ & $46.1(27.0-143.1)$ \\
\hline
\end{tabular}

${ }^{a}$ Effective dose, concentration, or time $50 \%$; chlorpyrifos: $\mathrm{LD}_{50}$ expressed as $\mathrm{ng} / \mathrm{mg}$; hydramethylnon: $\mathrm{LC}_{50}$ expressed as $\mu \mathrm{g} / \mu \mathrm{l} ;$ none: $\mathrm{LT}_{50}$ expressed as days.

potentiate the toxicity of a respiratory poison, like hydramethylnon. T. solenopsae-infected workers were 2.4-fold more susceptible to hydramethylnon than uninfected workers in toxicity bioassays. Insecticide potentiation by a microbial infection has been reported with boric acid and Metarhizium anisopliae (Metschnikoff) Sorokin in the German cockroach. Zurek et al. (2002) reported that the toxicity of $M$. anisopliae could be increased 2-fold with co-application of boric acid. Furthermore, in a more directly related example, the efficacy of Beauveria bassiana (Balsamo) Vuillemin has been shown to be significantly higher against $T$. solenopsae-infected S. invicta (Brinkman and Gardner, 2000).

When chlorpyrifos was evaluated against $T$. solenopsae-infected and uninfected workers, no significant difference was observed in the toxicity level. We also compared mortality among infected and uninfected colonies in the absence of any treatment. When provided only water, $T$. solenopsae-infected workers died significantly (6-fold) more rapidly than uninfected workers. These data illustrate the detrimental effects of $T$. solenopsae infection on $S$. invicta survival. Williams et al. (1999) similarly reported a significant increase in worker mortality after inoculation of a healthy colony of $S$. invicta with $T$. solenopsae. They also showed that infection resulted in decreases in egg production, brood volume, and queen weight.

We conducted an experiment to examine whether $T$. solenopsae infection would increase hydramethylnon efficacy in the field. In the pasture treated with hydramethylnon the number of $T$. solenopsae-infected colonies decreased much faster than uninfected colonies in the same area (Fig. 3). The initial change in the number of fire ant mounds decreased rapidly from 25 mounds/plot to just under 7 mounds/plot in 2 weeks. The initial rate of decline (over the first 2 weeks) was 1.3 mounds/plot/day among $T$. solenopsae-infected colonies compared with a decrease of 0.4 mounds/plot/day among uninfected colonies. After the initially rapid decline, no significant differences in mound changes were observed between infected and uninfected colonies. The rapid decline in the $T$. solenopsae-infected field populations was similar to that observed in our laboratory

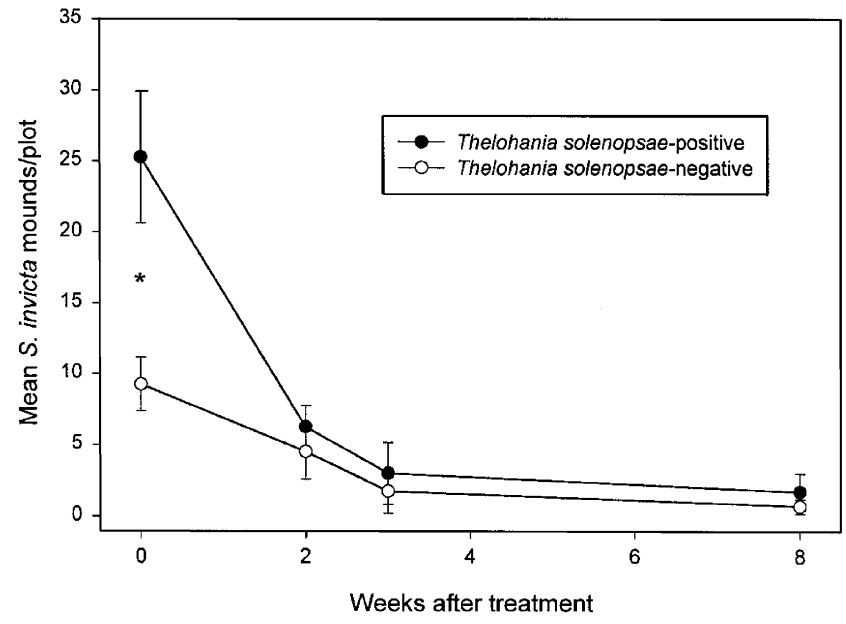

Fig. 3. Changes in the mean number of Thelohania solenopsae-infected and -uninfected fire ant mounds after field treatment with hydramethylnon (Siege-Pro). Means (by time point) indicated with an asterisk are significantly different $(t=5.6)$ from the control ( $T$. solenopsae negative) by Student's $t$ test.

experiments. Regardless of infection, hydramethylnon treatment reduced the number of mounds/plot to less than 3 within 8 weeks.

Thelohania solenopsae is widely present within polygynous $S$. invicta in some areas of the United States; the infection rate in some areas of Florida is above 50\% (RMP, unpublished data). Alone, the entomopathogen $T$. solenopsae results in a decline in red imported fire ant colony members, culminating in colony death (Oi and Williams, 2002). Unfortunately, colony demise is effected only after extended durations of infection (months to years). Our results show that detrimental effects of $T$. solenopsae infection can be significantly improved and accelerated (3-fold) with hydramethylnon treatment. The combination of the microsporidium, $T$. solenopsae, and hydramethylnon provides an excellent example of an integrated approach to controlling the red imported fire ant. This approach, combined with the use of the Pseudacteon spp., parasitic phorid flies, is being tested currently in a large-scale, USDA-sponsored areawide project in Florida, Mississippi, Oklahoma, South Carolina, and Texas. 


\section{Acknowledgments}

We thank C.A. Strong, J.D. Hall, D.E. Milne, S.A. Reidel, and M.E. Ruiz for technical assistance and Drs. D.H. Oi (USDA-ARS) and S.J. Yu (University of Florida) for critically reviewing the manuscript.The use of trade, firm, or corporation names in this publication are for the information and convenience of the reader. Such use does not constitute an official endorsement or approval by the United States Department of Agriculture or the Agricultural Research Service of any product or service to the exclusion of others that may be suitable.

\section{References}

Abbott, W.S., 1925. A method of computing the effectiveness of an insecticide. J. Econ. Entomol. 18, 265-267.

Briano, J., Patterson, R., Cordo, H., 1995. Relationship between colony size of Solenopsis richteri (Hymenoptera: Formicidae) and infection with Thelohania solenopsae (Microsporidia: Thelohaniidae) in Argentina. J. Econ. Entomol. 88, 1233-1237.

Brinkman, M.A., Gardner, W.A., 2000. Enhanced activity of Beauveria bassiana to red imported fire ant workers (Hymenoptera: Formicidae) infected with Thelohania solenopsae. J. Agric. Urban Entomol. 17, 191-195.

Finney, D.J., 1971. Probit Analysis. Cambridge University Press, Cambridge.

Hollingshaus, J.G., 1987. Inhibition of mitochondrial electron transport by hydramethylnon, a new amidinohydrazone insecticide. Pest. Biochem. Physiol. 27, 61-70.

Jouvenaz, D.P., Allen, G.E., Banks, W.A., Wojcik, D.P., 1977. A survey for pathogens of fire ants, Solenopsis spp., in the southeastern United States. Fla. Entomol. 60, 275-279.

Katinka, M.D., Duprat, S., Cornillot, E., Metenier, G., Thomarat, F., Prensier, G., Barbe, V., Peyretaillade, E., Brottier, P., Wincker, P., Delbac, F., El Alaoui, H., Peyret, P., Saurin, W., Gouy, M., Weissenbach, J., Vivares, C.P., 2001. Genome sequence and gene compaction of the eukaryote parasite Encephalitozoon cuniculi. Nature 414, 450-453.
Lofgren, C.S., Banks, W.A., Glancey, B.M., 1975. Biology and control of imported fire ants. Annu. Rev. Entomol. 20, 1-30.

Mathis, A., 2000. Microsporidia: emerging advances in understanding the basic biology of these unique organisms. Int. J. Parasitol. 30, 795-804.

Oi, D.H., Williams, D.F., 2002. Impact of Thelohania solenopsae (Microsporidia: Thelohaniidae) on polygyne colonies of red imported fire ants (Hymenoptera: Formicidae). J. Econ. Entomol. 95, 558-562.

Porter, S.D., Fowler, H.G., Mackay, W.P., 1992. Fire ant mound densities in the United States and Brazil (Hymenoptera: Formicidae). J. Econ. Entomol. 85, 1154-1161.

SAS Institute. 1988. SAS procedures guide for personal computers. SAS Institute, Cary, NC.

Weidner, E., 1970. Ultrastructural study of microsporidian development. I. Nosema sp. Sprague, 1965 in Callinectes sapidus Rathbun. Z. Zellforsch. 105, 33-54

Weidner, E., Findley, A.M., Dolgikh, V., Sokolova, J., 1999. Microsporidian biochemistry and physiology. In: Wittner, M., Weiss, L.M. (Eds.), The Microsporidia and Microsporidiosis. American Society of Microbiology, Washington, DC, pp. 172195.

Williams, D.F., Collins, H.L., Oi, D.H., 2001. The red imported fire ant (Hymenoptera: Formicidae): an historical perspective of treatment programs and the development of chemical baits for control. Am. Entomol. 47, 146-159.

Williams, D.F., Knue, G.J., Becnel, J.J., 1998. Discovery of Thelohania solenopsae from the imported fire ant, Solenopsis invicta, in the United States. J. Invertebr. Pathol. 71, 175176.

Williams, D.F., Lofgren, C.S., Plumley, J.K., Hicks, D.M., 1983. Auger-applicator for applying small amounts of granular pesticides. J. Econ. Entomol. 76, 395-397.

Williams, D.F., Oi, D.H., Knue, G.J., 1999. Infection of red imported fire ant (Hymenoptera: Formicidae) colonies with the entomopathogen Thelohania solenopsae (Microsporidia: Thelohaniidae). J. Econ. Entomol. 92, 830-836.

Williams, B.A.P., Hirt, R.P., Lucocq, J.M., Embley, T.M., 2002. A mitochondrial remnant in the microsporidian Trachipleistophora hominis. Nature 418, 865-869.

Zurek, L., Watson, D.W., Schal, C., 2002. Synergism between Metarhizium anisopliae (Deuteromycota: Hyphomycetes) and boric acid against the German cockroach (Dictyoptera: Blattellidae). Biol. Control 23, 296-302. 